\title{
Влияние химической обработки и топологии поверхности на блокирующее напряжение GaAs тиристорных мезаструктур, выращенных методом ГФЭ МОС
}

\author{
(C) А.Б. Чигинева, Н.В. Байдусь, С.М. Некоркин, К.С. Жидяев, В.Е. Котомина, И.В. Самарцев
}

Нижегородский государственный университет им. Н.И. Лобачевского, 603022 Нижний Новгород, Россия

E-mail: chigineva@nifti.unn.ru

Поступила в Редакцию 25 августа 2021 г.

В окончательной редакции 14 сентября 2021 г.

Принята к публикации 14 сентября 2021 г.

Исследовано влияние на блокирующую способность GaAs тиристорных мезаструктур сульфидной пассивации (химической обработки в перекисно-серном травителе и в растворе $\mathrm{Na}_{2} \mathrm{~S}$ в изопропаноле) и усложнения профиля боковой поверхности мез. Показано, что блокирующее напряжение чипов возрастает в несколько раз как после химической обработки поверхности, так и при усложнении топологии поверхности.

Ключевые слова: тиристоры, блокирующее напряжение, сульфидная пассивация, арсенид галлия, мезаструктура.

DOI: 10.21883/FTP.2022.01.51824.9732

\section{1. Введение}

Тиристоры на основе арсенида галлия, выращенные методом газофазной эпитаксии из металлоорганических соединений (ГФЭ МОС), привлекают в последнее время внимание исследователей с точки зрения создания низковольтных сильноточных ключей, применяемых, например, для решения проблемы генерации коротких импульсов тока большой амплитуды в цепях с низкоимпедансной нагрузкой [1]. Практически все известные на сегодняшний день исследования по созданию $\mathrm{A}^{\mathrm{III}} \mathrm{B}^{\mathrm{V}}$ тиристоров (в том числе на GaAs-структурах) проводились с высоковольтными конструкциями, выращенными методом жидкофазной эпитаксии [2,3]. В основе этих конструкций были толстые (от десятков до сотен микрометров), слаболегированные $\left(\sim 10^{14}-10^{15} \mathrm{~cm}^{-3}\right)$ базовые слои, обеспечивающие напряжение переключения $\sim 1$ кВ. Однако эти решения неэффективны, когда нагрузка имеет низкое сопротивление [1]. Метод ГФЭ МОС позволяет выращивать тонкие слои (от десятых долей до единиц микрометров) с уровнем легирования $\sim 10^{16} \mathrm{~cm}^{-3}$. В $[4,5]$ была показана возможность создания этим методом низковольтных тиристоров различных конструкций с напряжением переключения до 35 В на основе GaAs и его твердых растворов. При этом подчеркивалась необходимость поиска эффективных способов пассивации боковой поверхности чип-тиристоров, поскольку утечки по поверхностным состояниям приводят к большому разбросу напряжения переключения образцов. Так как полный процесс изготовления чиптиристоров достаточно трудоемкий, то удобнее изучать эффекты пассивации на мезаструктурах.

Одним из основных параметров тиристора, как полупроводникового прибора, является напряжение переключения из закрытого состояния (с низкой проводи- мостью) в открытое (с высокой проводимостью) [6]. Однако для тиристорных мезаструктур более корректно применять понятие блокирующее напряжение („,blocking voltage“ [7]) или блокируемое напряжение [8], которое соответствует максимальному напряжению $\left(U_{B}\right)$ в состоянии с низкой проводимостью. Дальнейшее повышение напряжения приводит к резкому нарастанию тока в цепи. Заметим, что вклад в нарастание тока при $U \geq U_{B}$ может давать как объемная проводимость через тиристорную структуру за счет лавинного размножения носителей в сильном электрическом поле обратно смещенного коллекторного $p-n$-перехода, так и проводимость, связанная с утечками, которые в значительной степени обусловлены высокой плотностью поверхностных состояний по периметру $p-n$-переходов [9]. Причем вклад от второй составляющей может превышать вклад от первой. Благодаря этому пробой у поверхности начинается при меньших значениях обратного напряжения смещения, чем в объеме.

Химическая обработка растворами электролитов позволяет эффективно модифицировать электронные характеристики $\mathrm{A}^{\mathrm{III}} \mathrm{B}^{\mathrm{V}}$ полупроводниковых поверхностей и интерфейсов с целью повышения эффективности различных полупроводниковых приборов на их основе [10]. Для электронной и химической пассивации поверхностных состояний арсенида галлия наиболее активно используется обработка сульфидными растворами (сульфидная пассивация) $[10,11]$. Положительное влияние пассивации на параметры приборных структур на основе GaAs и его твердых растворов было продемонстрировано для силовых диодов [9], лазеров [12], фотоприемников [13,14], биполярных и полевых транзисторов [15]. При этом отмечается, что один и тот же метод пассивации может приводить к принципиально разным результатам для приборов различной конструкции, даже выполненных 
из одинаковых материалов [10]. Поэтому для каждой конкретной структуры нужно подбирать оптимальные режимы пассивации.

Существенной причиной снижения блокирующей способности многослойных полупроводниковых приборов, диодов и тиристоров (как кремниевых, так и $\mathrm{A}^{\mathrm{III}} \mathrm{B}^{\mathrm{V}}$ ), является образование в местах выхода $p-n$-переходов на боковую поверхность мез инверсионных каналов, которые сильно увеличивают токи утечки $[16,17]$. В случае массивных $\mathrm{Si}$-тиристоров (диаметром в несколько сантиметров) для повышения блокирующего напряжения снижают электрическое поле $p-n$-перехода на боковой поверхности путем механического профилирования (создания фасок) [18,19]. При этом отмечается, что для малогабаритных чипов диаметром в несколько миллиметров экономически целесообразно проводить групповую обработку методами травления.

Настоящая работа посвящена исследованию возможности повышения блокирующего напряжения низковольтных GaAs тиристорных мезаструктур путем химической обработки их боковой поверхности в перекисносерном травителе и в растворе $\mathrm{Na}_{2} \mathrm{~S}$ в изопропиловом спирте $\left(i-\mathrm{C}_{3} \mathrm{H}_{7} \mathrm{OH}\right)$, а также путем создания сложно профилированной ступенчатой топологии боковой поверхности мезы методом жидкостного травления.

\section{2. Исследуемые образцы и методика эксперимента}

Тиристорные структуры выращивались методом ГФЭ MOC на подложках $n^{+}$-GaAs (100) толщиной 450 мкм и представляли собой четырехслойную $n-p-n-p$ конструкцию из слоев арсенида галлия, легированных кремнием ( $n$-тип) и углеродом ( $p$-тип). Эмиттерные слои толщиной 0.3 мкм легировались до концентрации $2 \cdot 10^{17} \mathrm{~cm}^{-3}$. Базовая область $p$-типа имела толщину 2 мкм, концентрацию носителей заряда $3.5 \cdot 10^{16} \mathrm{~cm}^{-3}$. Во второй базе толщиной 1.9 мкм концентрация носителей была снижена до $2 \cdot 10^{16} \mathrm{~cm}^{-3}$.

$\mathrm{C}$ помощью фотолитографии и химического травления в растворе $\mathrm{H}_{3} \mathrm{PO}_{4}: \mathrm{H}_{2} \mathrm{O}_{2}: \mathrm{H}_{2} \mathrm{O}=1: 1: 5$ из пластины с выращенной структурой изготавливались образцы двух типов: 1) с простой круглой мезаструктурой (первый тип) и 2) с круглой мезой со сложным ступенчатым профилем (второй тип). Одиночные мезы первого типа диаметром $d \approx 2$ мм вытравливались до $n$-базы (глубина травления $h=0.6$ мкм) или до подложки $(h=5.5$ мкм). Образцы второго типа изготавливались путем последовательного вытравливания трех соосных мез (рис. 1): первая меза имела глубину $h_{1}=5.5$ мкм и диаметр $d_{1}=4$ мм; вторая меза: $h_{2}=0.7$ мкм, $d_{2}=2.7$ мм и третья меза: $h_{3}=0.3$ мкм, $d_{3}=0.8$ мм. Из пластин выкалывались чипы размером $5 \times 5$ мм с одной мезаструктурой (простой или ступенчатой) на каждом. Со стороны подложки на каждом чипе формировался точечный омический контакт методом электроискрового вжигания

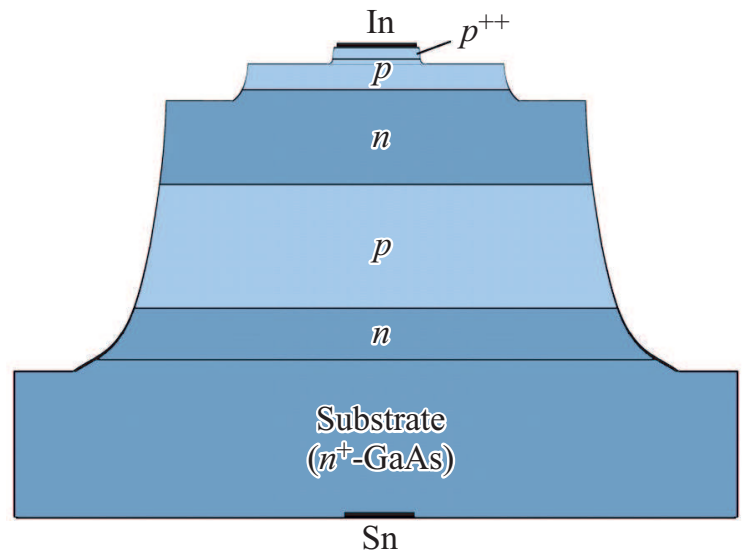

Рис. 1. Схематическое изображение образца второго типа (чип со ступенчатыми мезами).

оловянной фольги. Со стороны структуры использовался In-контакт.

В работе применялись два способа химической обработки поверхности изготовленных мезаструктур. Первый способ включал погружение образцов на 1-2 с в перекисно-серный травитель (ПСТ), состоявший из концентрированной серной кислоты, $33 \%$ перекиси водорода и деионизированной воды $\mathrm{H}_{2} \mathrm{SO}_{4}: \mathrm{H}_{2} \mathrm{O}_{2}: \mathrm{H}_{2} \mathrm{O}=4: 1: 15$. Затем образцы промывались и высушивались на воздухе. Второй способ включал описанную выше предварительную обработку в ПСТ и последующую сульфидную пассивацию путем погружения образцов на 3 мин в насыщенный раствор $\mathrm{Na}_{2} \mathrm{~S}$ в $i-\mathrm{C}_{3} \mathrm{H}_{7} \mathrm{OH}$ при комнатной температуре с дополнительным освещением лампой накаливания мощностью 200 Вт. После пассивации чипы также промывались и высушивались на воздухе.

Вольт-амперные характеристики (BAX) тиристорных мезаструктур измерялись в режиме источника напряжения до и после химической обработки.

\section{3. Результаты и обсуждение}

На рис. 2 приведены типичные ВАХ образца первого типа с одиночной мезой глубиной 0.6 мкм до и после химической обработки. Видно, что после обработки образцов в перекисно-серном травителе блокирующее напряжение возросло от $18 \mathrm{~B}$ до $\sim 30 \mathrm{~B}$ (рис. 2, кривые 1,2$)$. Комбинированная обработка поверхности мезаструктур в ПСТ и в сульфидном растворе позволила дополнительно повысить $U_{B}$ до 32 В (рис. 2, кривая 3). При этом величина обратного тока уменьшилась на 2 порядка (от $10^{-5} \mathrm{~A}$ до $10^{-7} \mathrm{~A}$ при обратном напряжении $\left.U_{R}=-20 \mathrm{~B}\right)$, что связано, очевидно, со снижением плотности поверхностных состояний при удалении естественного окисла и образовании пассивирующего сульфидного покрытия на боковой поверхности мезаструктур $[10,11]$. Время проявления эффекта пассивации 


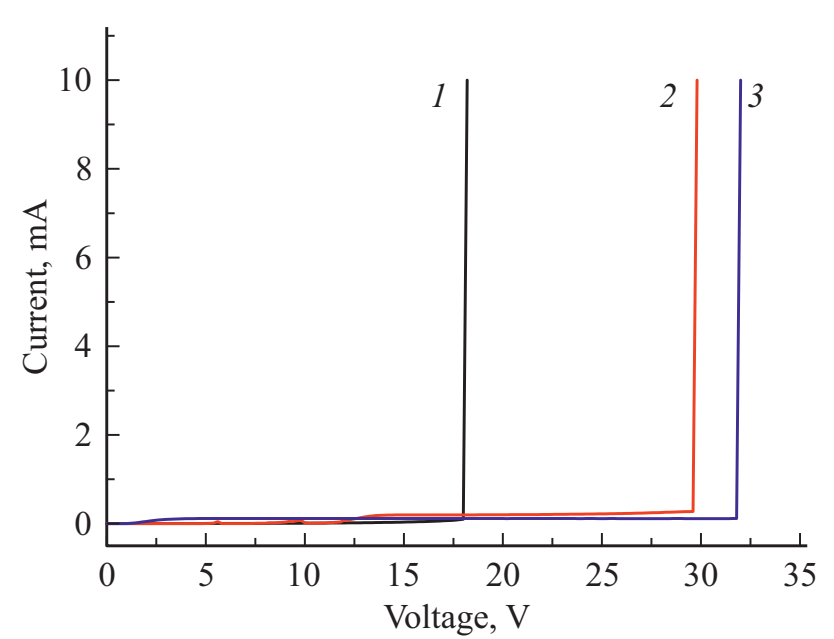

Pис. 2. Типичные BAX (в режиме источника напряжения) образца первого типа с одиночной мезой глубиной 0.6 мкм: до обработки (1), после обработки в ПСТ (2), после обработки в ПСТ и сульфидной пассивации в растворе $\mathrm{Na}_{2} \mathrm{~S}(3)$.

при хранении образцов на воздухе при естественном освещении составляло $\sim 30$ мин. Это согласуется с данными работ из обзора [11], в которых обнаружено, что при выдержке поверхности GaAs в атмосфере и при освещении пассивирующий эффект деградировал в течение 30-40мин за счет образования слоя естественного окисла. Причем скорость окисления пассивированной поверхности сильно зависела от ориентации поверхности: быстрее всех окислялась поверхность (100) [20]. Поэтому описанная выше методика обработки может применяться, например, для проведения быстрой диагностики тиристорных характеристик выращенной структуры перед постростовой обработкой пластины. B технологии изготовления GaAs-тиристоров она может использоваться только в сочетании с дополнительной защитой поверхности (например, с помощью защитного диэлектрического покрытия).

Отметим, что резкий рост тока через мезаструктуру при напряжениях $U \geq U_{B}$ часто сопровождается пробоем (в том числе поверхностным) и деградацией тиристорной структуры. Мы обнаружили, что блокирующая способность чипов может быть восстановлена, если удалить естественный окисел путем стравливания тонкого приповерхностного слоя или при изготовлении свежих сколов на краях чипов. Это подтверждает поверхностную природу пробоя мезаструктуры. Исследованная в данной работе обработка поверхности мез направлена как раз на снижение деградационных эффектов за счет обеспечения возможно меньшего по величине и стабильного во времени поверхностного заряда. Полученные результаты могут быть использованы в технологии изготовления реальных приборов.

Вытравливание одиночной мезы до подложки $(h=5.5$ мкм $)$ на образцах первого типа значительно ухудшало блокирующую способность чипов. Участок быстрого нарастания тока начинался уже при напряжении $U_{B} \approx 3-7 \mathrm{~B}$, что может быть связано с увеличением электрического поля на боковой поверхности глубокой мезы за счет выхода на эту поверхность трех $p-n$-переходов (тогда как в случае мелкой мезы на ее поверхность выходит только один прямосмещенный $p-n$-переход).

Известно, что жидкостное травление не позволяет получить вертикальные стенки мез, они имеют вогнутый вид (аналог прямой и обратной фасок). Будут ли эти фаски давать положительный эффект (увеличивая блокирующую способность структуры) или, напротив, будут оказывать отрицательное влияние, в большой степени зависит от того, где окажется выход на боковую поверхность центрального блокирующего перехода. С помощью микроскопа LEICA DM 4000 М мы исследовали форму боковой поверхности травления мез. Для этого были изготовлены вертикальные сколы в плоскости, проходящей через центр мезаструктуры перпендикулярно ее слоям. Оказалось, что травление глубокой мезы создает в области центрального коллекторного $p-n$ перехода прямую фаску под углом $\sim 45^{\circ}$. Из литературы известно, что для такого угла в кремниевых тиристорах напряженность поля на поверхности максимальна [18], что резко повышает вероятность поверхностного пробоя. На поверхности обратной фаски напряженность поля существенно снижается в сравнении с напряженностью поля в объеме при всех углах этой фаски. Однако получить обратную фаску на столь малых объектах технически затруднительно, поэтому поиск путей защиты от поверхностного пробоя продолжается. При изучении перспектив защиты высоковольтных мезаэпитаксиальных 4H-SiC-диодов от краевого пробоя путем формирования мезаструктур с наклонными стенками, образующими прямую фаску, авторы [21] пришли к выводу, что вместо вертикальных стенок более эффективным могло бы стать формирование мезаструктур с наклонными стенками. Как показало моделирование, при формировании прямой фаски в $4 H$-SiC-приборах с $p-n_{0}$-переходом нет необходимости вытравливать мезаструктуру до $n$-подложки (глубина травления 10 мкм): достаточно протравить ее до плоскости $p-n_{0}$-перехода на глубину 1.5-2 мкм. Это согласуется с полученными нами результатами, согласно которым максимальное блокирующее напряжение соответствует тиристорным мезаструктурам с одиночной мезой, вытравленной до $n$-базы.

Как отмечалось выше, для увеличения блокирующей способности многослойных полупроводниковых структур используется профилирование (создание фасок), снижающее электрическое поле $p-n$-перехода на боковой поверхности структуры и, следовательно, утечки по поверхностным состояниям. Основываясь на анализе сведений из литературы и наших экспериментальных данных, нами была разработана трехступенчатая геометрия мез, описанная в предыдущем разделе (образцы 


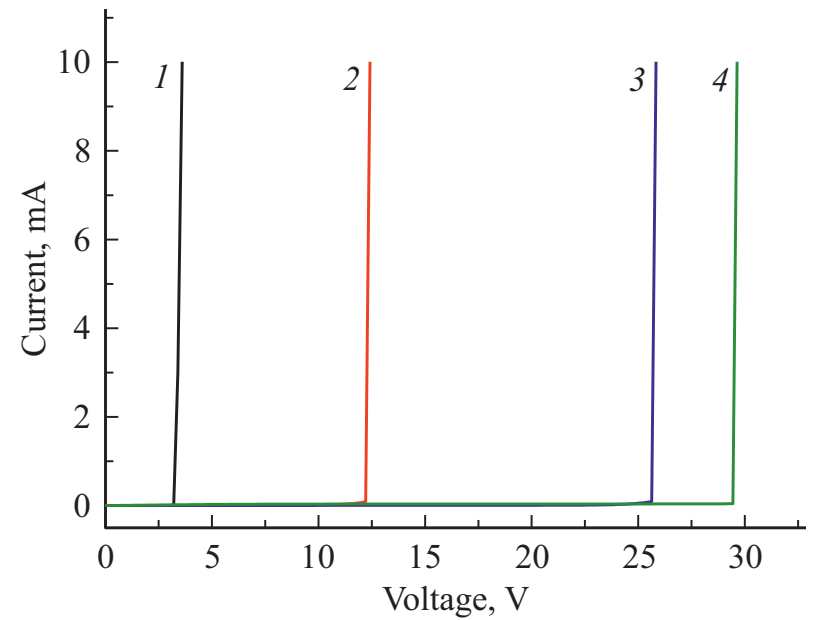

Pис. 3. Типичные BAX (в режиме источника напряжения) образца второго типа со ступенчатым профилем мез: 1 - одна меза $h_{1}=5.5$ мкм; $2-$ две мезы: $h_{1}$ и $h_{2}=0.7$ мкм; $3-$ три мезы: $h_{1}, h_{2}$ и $h_{3}=0.3$ мкм; $4-$ три мезы и сульфидирование.

второго типа). Глубины и диаметры соосных мез выбирались таким образом, чтобы уменьшить токи утечки по поверхностным состояниям стенок мез, в том числе за счет снижения напряженности электрического поля в местах выхода $p-n$-переходов на боковую поверхность мез. После травления каждой мезы измерялись ВАХ чипов, и фиксировалось блокирующее напряжение $U_{B}$ (рис. 3, кривые 1-3). Оказалось, что усложнение топологии поверхности образцов приводит к повышению величины $U_{B}$ структуры почти на порядок (от 3 до $25.5 \mathrm{~B})$. Такое изменение $U_{B}$ для сложнопрофилированной структуры может быть связано, с одной стороны, с отдалением от боковой поверхности мезы сильнолегированного контактного слоя (меза 3), что затрудняет проводимость по поверхностным состояниям. С другой стороны, ступенчатый профиль мез в какой-то мере аналогичен фаскам с мезаподобным контуром, предложенным для кремниевых тиристоров [22], благодаря которым поверхностные электрические поля снижаются по сравнению с полями в объеме материала, что препятствует поверхностному пробою структуры. В результате пробой коллекторного перехода происходит при большем напряжении.

Обработка развитой поверхности образцов второго типа в ПСТ и в спиртовом растворе $\mathrm{Na}_{2} \mathrm{~S}$ позволила дополнительно повысить блокирующую способность до 29 В (рис. 3, кривая 4), что также отражает снижение плотности поверхностных состояний на боковой поверхности мезаструктур за счет формирования сульфидного пассивирующего покрытия. Однако нужно заметить, что при повторных измерениях ВАХ наблюдалась постепенная деградация блокирующей способности чипов второго типа. Следовательно, необходима дополнительная защита пассивированной поверхности.
Сравнение данных на рис. 2 и 3 показывает, что оба способа обработки мезаструктур, применявшиеся нами, позволяют достичь величины блокирующего напряжения $U_{B} \sim 30$ В. При этом первый способ намного проще с точки зрения технологии изготовления. Однако результаты, полученные при втором способе обработки, могут быть полезны при разработке приборных структур с более сложной конфигурацией, например, тиристоров с управляющим контактом.

Из литературы известно, что традиционные методы борьбы с поверхностным пробоем, хорошо зарекомендовавшие себя при изготовлении кремниевых приборов, - профилирование, химическая обработка и защита боковой поверхности диэлектриком, - для арсенид-галлиевых $p-n$-переходов, как правило, оказываются недостаточно эффективными и не позволяют решить проблему полностью. Для расширения диапазона рабочих напряжений и повышения надежности GaAs-приборов применялось протонное и электронное облучение периферийных областей с энергией $E=(3-5)$ МэВ и дозами $10^{12}-10^{13} \mathrm{~cm}^{-2}$ [23]. При протонном облучении $n$-GaAs резко уменьшается его электропроводность, он становится высокоомным и даже полуизолирующим, что связывается с появлением в запрещенной зоне полупроводника глубоких акцепторов. Исследования выращенных методом жидкофазной эпитаксии силовых импульсных диодов и динисторов на основе GaAs показали, что „низковольтный“ пробой в необлученных структурах происходил в области краевого мезаконтура $p-n$-перехода. После протонного облучения наблюдалось резкое увеличение толщины области пространственного заряда в периферийной (облученной) части кристалла и повышение напряжения лавинного пробоя от типичных значений $600-800$ В до уровня $>1000$ В. Недостатком такой обработки является радиоактивность образцов после облучения вследствие инициирования ядерных реакций высокоэнергетичными протонами.

Для закрепления описанного нами эффекта повышения блокирующей способности GaAs тиристорных мезаструктур путем химической обработки их боковой поверхности, а также путем создания развитой боковой поверхности мезы можно применить протонную бомбардировку. В дальнейшем мы планируем провести детальное изучение этого вопроса.

\section{4. Заключение}

Таким образом, исследовано влияние химической обработки боковой поверхности GaAs тиристорных мезаструктур, а также создания сложного многоступенчатого профиля боковой поверхности мезы на величину блокирующего напряжения образцов. Показана возможность повышения предельного значения $U_{B}$ до $30-32 \mathrm{~B}$. Это еще раз демонстрирует важность поиска эффективных способов модификации электронных свойств поверх- 
ности арсенида галлия и приборных структур на его основе.

\section{Финансирование работы}

В части разработки технологии постростовых операций экспериментальных образцов исследование выполнено за счет государственного задания ННГУ им. Н.И. Лобачевского.

\section{Конфликт интересов}

Авторы заявляют, что у них нет конфликта интересов.

\section{Список литературы}

[1] S.O. Slipchenko, A.A. Podoskin, V.S. Golovin, P.S. Gavrina, V.V. Shamakhov, D.N. Nikolaev, V.V. Zolotarev, N.A. Pikhtin, T.A. Bagaev, M.A. Ladugin, A.A. Marmalyuk, V.A. Simakov. IEEE Trans. on Electron Dev., 67 (1), 193 (2020).

[2] В.И. Корольков, Н. Рахимов. Диоды, транзисторы и тиристоры на основе гетероструктур (Ташкент, Фан, 1986).

[3] R.J. Lis, J.H. Zhao, L.D. Zhu, J. Illan, S. McAfee, T. Burke, M. Weiner, W.R. Buchwald, K.A. Jones. IEEE Trans. Electron Dev., 84 (5), 809 (1994).

[4] А.Б. Чигинева, С.М. Некоркин, Н.В. Байдусь, И.В. Самарцев, К.С. Жидяев, Е.В. Демидов, А.В. Крюков, В.А. Токарев, Д.И. Баклашов. Матер. XXIII Международ. симп. „Нанофизика и наноэлектроника“. (Н. Новгород, Россия, $2019)$ т. 2, с. 874.

[5] А.Б. Чигинева, С.М. Некоркин, Н.В. Байдусь, К.С. Жидяев, А.В. Крюков, В.А. Токарев, Д.И. Баклашов. Матер. XXIV Междунар. симп. „Нанофизика и наноэлектроника“. (Н. Новгород, Россия, 2020) т. 2, с. 794.

[6] ГОСТ 20332-84 Тиристоры. Термины, определения и буквенные обозначения. - Взамен ГОСТ 20332-74; введ. 01.07.1985. - docs.cntd.ru/document/1200015690

[7] S.O. Slipchenko, A.A. Podoskin, O.S. Soboleva, N.A. Pikhtin, T.A. Bagaev, M.A. Ladugin, A.A. Marmalyuk, V.A. Simakov, I.S. Tarasov. J. Appl.Phys., 121, 054502 (2017).

[8] А.А. Подоскин, П.С. Гаврина, В.С. Головин, С.О. Слипченко, Д.Н. Романович, В.А. Капитонов, И.В. Мирошников, Н.А. Пихтин, Т.А. Багаев, М.А. Ладугин, А.А. Мармалюк, В.А. Симаков. ФТП, 55 (5), 466 (2021).

[9] М. Бонтарюк, Ю.В. Жиляев, Е.В. Коненкова. ФТП, 33 (6), 716 (1999).

[10] М.В. Лебедев. ФТП, 54 (7), 587 (2020).

[11] В.Н. Бессолов, М.В. Лебедев. ФТП, 32 (11), 1281 (1998).

[12] N.V. Kryzhanovskaya, E.I. Moiseev, Yu.S. Polubavkina, F.I. Zubov, M.V. Maximov, A.A. Lipovskii, M.M. Kulagina, S.I. Troshkov, V.M. Korpijarvi, T. Niemi, R. Isoaho, M. Guina, M.V. Lebedev, T.V. Lvova, A.E. Zhukov. J. Appl.Phys., 120, 233103 (2016).

[13] М.В. Лебедев, В.В. Шерстнев, Е.В. Куницына, И.А. Андреев, Ю.П. Яковлев. ФТП, 45 (4), 535 (2011).

[14] Min-Su Park, M. Razaei, K. Barnhart, Ch.L. Tan, H. Mohseni. J. Appl. Phys., 121, 233105 (2017).

[15] R.K. Oxland, F. Rahman. Semicond. Sci. Technol., 23, 085020 (2008).

[16] А.С. Кюрегян. ФТП, 45 (3), 372 (2011).
[17] С.Н. Вайнштейн, Ю.В. Жиляев, М.Е. Левинштейн. Письма в ЖТФ, 14 (16), 1526 (1988).

[18] А. Блихер. Физика тиристоров (Л., Энергоиздат, 1981). [Пер. с англ.: А. Blicher. Thyristor physics (N.Y-Heidelberg-Berlin, Springer Verlag, 1976)].

[19] П. Тейлор. Расчет и проектирование тиристоров (М., Энергоатомиздат, 1990). [Пер. с англ.: Р. Taylor. Thyristor design and realization (Chichester, John Wiley \& Sons Ltd., 1987)].

[20] M. Oshima, T. Scimeca, Y. Watanabe, H. Oigawa, Y. Nannichi. Jpn. J. Appl. Phys., 32 (1S), 518 (1993).

[21] Н.М. Лебедева, Н.Д. Ильинская, П.А. Иванов. ФТП, 54 (2), 207 (2020)

[22] G. Kohl. Solid State Electron., 11 (4), 501 (1968).

[23] В.А. Козлов, В.В. Козловский. ФТП, 35 (7), 769 (2001).

Редактор Г.А. Оганесян

\section{Influence of chemical treatment and surface topology on the blocking voltage of GaAs thyristor mesastructures grown by MOCVD}

\section{A.B. Chigineva, N.V. Baidus, S.M. Nekorkin, K.S. Zhidyaev, V.E. Kotomina, I.V. Samartsev}

Nizhny Novgorod State University, 603022 Nizhny Novgorod, Russia

Abstract The effect of sulfide passivation (chemical treatment in a peroxide-sulfur etchant and in a solution of $\mathrm{Na}_{2} \mathrm{~S}$ in isopropanol) and complication of the profile of the lateral surface of thyristor mesastructures on the blocking ability of GaAs thyristor mesastructures is investigated. It is shown that the blocking voltage of the chips increases several times both after chemical treatment of the surface and with the complication of the surface topology. 